Original Paper

\title{
Long Noncoding RNA Lnc-SEMT Modulates IGF2 Expression by Sponging miR-125b to Promote Sheep Muscle Development and Growth
}

\author{
Caihong Weia Mingming Wu ${ }^{a, b} \quad$ Chuduan Wang ${ }^{b}$ Ruizao Liu ${ }^{a}$ \\ Huijing Zhao ${ }^{a}$ Li Yang ${ }^{c}$ Jiafan Liuc Yayu Wang ${ }^{c}$ Shuzhen Zhang ${ }^{a}$ \\ Zehu Yuan ${ }^{\mathrm{a}}$ Zhen Liu ${ }^{\mathrm{a}}$ Shijin $\mathrm{Hu}^{\mathrm{a}}$ Mingxing Chu ${ }^{\mathrm{a}}$ Xiaogang Wang ${ }^{\mathrm{c}}$ \\ Lixin Dua
}

aInstitute of Animal Sciences, Chinese Academy of Agricultural Sciences, Beijing, ${ }^{b}$ College of animal science and technology, China Agricultural University, Beijing 'College of life science and technology, Jinan University, Guangzhou China

\section{Key Words}

LncRNA • myoblast differentiation • sheep muscularity $・$ miR-125b $・$ IGF2

\begin{abstract}
Background/Aims: Long noncoding RNAs (IncRNAs) are RNA transcripts that are more than $200 \mathrm{nt}$ long but have little protein-coding potential. Within the last few years, thousands of IncRNAs have been identified and their functions in biological processes have begun to be understood. Although many studies havebegun to examine the functions of many noncoding RNAs, very little is known about the functions of long noncoding (IncRNA) function of livestock production and molecular mechanisms of their functions are still lackingrelated to livestock production. Methods: Expression of sheep enhanced muscularityTranscript IncRNA (Inc-SEMT) and miR-125b were examined in sheep using quantitative reverse-transcription polymerase chain reaction. Expression of Myod (myogenic determination factor), Myog (myoglobin) and Insulin-like growth factor 2 (IGF2)were examined by Western Blot.Luciferase reporter assays were performedto confirm the relationship between Inc-SEMT and miR-125b. Results: Here, we identified a novel Inc-SEMT that promote sheep myoblast differentiation in vitro and enhanced sheep muscularity in vivo. Functional analyses showed that Inc-SEMT accelerates sheep myoblast differentiation in vitro. Inc-SEMT transgenic sheep exhibit a muscle hypertrophy phenotype characterized by increased body weight, and increased the number of muscle fibers indicating that Inc-SEMT play an important role in the regulation of skeletal muscle differentiation in vivo. Our results show that Inc-SEMT acts as a molecular sponge by
\end{abstract}

C. Wei and M. Wu contributed equally to this work.

Lixin Du

and Xiaogang Wang
Institute of Animal Sciences, Chinese Academy of Agricultural Sciences

2 Yuanmingyuan West Road, Beijing, 100193 (China)

Tel. 86-010-62818815, E-Mail Ixdu@263.net; txg_wang@jnu.edu.cn 


\section{Cellular Physiology Cell Physiol Biochem 2018;49:447-462

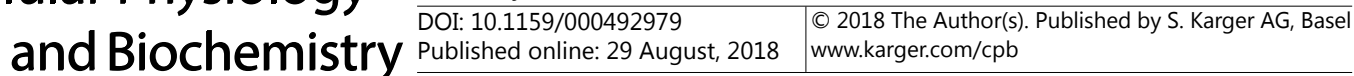 \\ Wei et al.: Lnc-SEMT Enhances Sheep Muscularity}

antagonizing miR-125b to control IGF2 protein labundancein vitro and in vivo. Conclusion: In brief, Inc-SEMT is the first example of a IncRNA could be a useful candidate for improving biological growth traits such as skeletal muscle production in sheep.

(C) 2018 The Author(s)

Published by S. Karger AG, Basel

\section{Introduction}

Domesticated sheep (Ovis aries) are large precocial mammals, and the maximum myofiber complement of their muscles is achieved prior to birth, especially during the second half of gestation [1]. The potential for muscle growth depends on the number of muscle fibers formed during the prenatal stage [2,3], with the greatest proliferation of fetal muscle fibers occurring during mid andto late pregnancy [4].

RNA molecules that are not translated into proteins are referred to as noncoding transcripts. These long noncoding RNAs (lncRNAs) represent a class of transcripts longer than 200 nucleotides with no protein-coding capacity [5, 6]. In the past decade, IncRNAs have rapidly become recognized as important regulators of gene expression in human disease $[7,8]$, and thousands of lncRNAs have been identified in several eukaryotes (mainly yeast) and model animal species $[9,10]$. So far, a large range of functions has been attributed to IncRNAs $[11,12]$ including coordinating the expression of genes involved in muscle growth, proliferation and differentiation $[13,14]$. Although thousands of large intergenic noncoding RNAs (lincRNAs) have been identified in mammals,relatively few have been functionally characterized, leading to debate about their biological role. So far, some lncRNAs have been shown to function as critical regulators of the transcriptional activity of target genes [15]. Other IncRNAs have also been found to act in the nucleus as antisense transcripts or as decoys for splicing factors which leads tomalfunctions in splicing $[16,17]$. In addition, some lncRNAs might act as competing endogenous RNAs (ceRNAs) that compete with proteincoding genes for binding to microRNAs (miRNAs) and other regulatory factors [18-20]. However, the number of lncRNAs identified as myogenic regulators so far is still exiguous thus the investigation of other species is required for defining the role of these transcripts in muscle specification. So although some studies have helped reveal the functions of IncRNAs in myogenesis and muscle development [21,22], very little is known about their functions and mechanisms in livestock meat production. The discovery and identification of skeletal muscle-specific lncRNAs in Ovis aries will further promote our understanding of the functions of IncRNAs andmechanisms by which they regulate the functions of target genes.

Insulin-like growth factor 2 (IGF2), also known as growth regulator A or somatomedin A, plays an important role in regulating fetal development, tumor proliferation and skeletal muscle growth. It is an embryonic regulator of myogenesis and an autocrine factor that initiates myoblast differentiation in vitro [23], whose expression istranscriptionally regulated by a muscle-specific enhancer via the mammalian target of rapamycin signaling pathway [24]. IGF2 also functions as a major growth factor that promotesand as an autocrine signal in muscle cell growth. The proportion of skeletal muscle in various animal taxa ranges from 40$60 \%$ [25-28]. As an essential factor for muscle cell differentiation [29, 30]. IGF2 can promote sheep muscle cell proliferation and differentiation by increasing the expression of $M y o D$ and myogenin [31]. In livestock, the growth and development of muscle tissue directly determines meat production. miRNAs, $\sim 22$-nt noncoding RNAs involved in posttranscriptional regulation of gene expression, have emerged as key regulators of many developmental processes [32, 33], including skeletal myogenesis. However, little is yet known about how the functions and mechanisms of these miRNAs might be relevant to livestock meat production.

In this study, we first used RNA-Seq to discover a IncRNA, Inc-SEMT, that is highly specifically expressed in sheep skeletal muscle tissue. Then, we found that lnc-SEMTcould competitively bind miR-125b to affect IGF2 expression and negatively modulate myoblast differentiation in vitro and in vivo in a transgenic (TG) animal model. We identify miR-125b as the molecular target of lnc-SEMTduring skeletal myogenesis. 


\section{Cellular Physiology Cell Physiol Biochem 2018;49:447-462 \begin{tabular}{ll|l} 
and Biochemistry Published onlıne: 29August, 2018 & $\begin{array}{l}\text { (c) } 2018 \text { The Author(s). Published by S. Karger AG, Basel } \\
\text { www.karger.com/cpb }\end{array}$ \\
\hline
\end{tabular} \\ Wei et al.: Lnc-SEMT Enhances Sheep Muscularity}

\section{Materials and Methods}

\section{Total RNA isolation and IncRNA sequencing}

Two Hu sheep fetuses at gestational ages of 90 days (-90) and 120 days $(-120)$ were used.for these experiments.Longissimus dorsi samples were excised andstored at $-80^{\circ} \mathrm{C}$ until RNA isolation. Total RNA was isolated from each muscle tissue sample using TRIzol reagent (Invitrogen,USA). RNA quality was monitored on $1.5 \%$ agarose gels and RNA concentration and purity were measured using the NanoDrop 2000 Spectrophotometer (Thermo Fisher, USA).RNA integrity was assessed using the RNA Nano 6000 Assay Kit with the Agilent Bioanalyzer 2100 System (Agilent Technologies, USA).After RNA quality control, a total of $1.5 \mu \mathrm{g}$ RNA per sample was used as input material for rRNA removal using the Ribo-Zero rRNA Removal Kit (Epicentre, USA). Sequencing libraries were generated usingNEBNext ${ }^{\circledast}$ Ultra $^{\mathrm{TM}} \mathrm{T}$ Directional RNA Library Prep Kit for Illumina ${ }^{\circledR}$ (NEB, USA) following manufacturer's recommendations and index codes were added tobe able to attribute sequences to each sample. Library quality was assessed on the Agilent Bioanalyzer 2100. The libraries were sequenced at the Biomarker Co.,Ltd. on an Illumina HiSeq 2500 platform to generate125-bp paired-end reads were generated.

\section{Analysis of IncRNAs}

Clean reads were obtained by excluding reads contain adapters, reads containing poly- $\mathrm{N}$ and low quality reads from the raw sequence data. All downstream analyses were performed on clean data. The embryonic sheep skeletal muscle transcriptome was assembled using Cufflinks [34] and Scripture [35] by mapping reads to the sheep reference genome. The assembled transcripts were annotated using the Cuffcompare program from the Cufflinks package. Unknown transcripts were screened for putative IncRNAs. Four computational approaches (CPC/CNCI/Pfam/CPAT) including the Coding Potential Calculator (CPC), the Coding-Non-Coding Index (CNCI), alignments to several protein family databases (Pfam), and the Coding Potential Assessment Tool (CPAT) were combined to sort noncoding RNA candidates from putative proteincoding RNAs among the unknown transcripts. Transcripts greater than $200 \mathrm{nt}$ in length with more than two exons were identified as IncRNA candidates and were further screened using CPC/CNCI/Pfam/CPATwhich are capable of distinguishing protein-coding genes. Furthermore, different types of IncRNAs including lincRNAs, intronic lncRNAs, anti-sense lncRNAs were identified using cuffcompare.

\section{Sheep myoblast isolation and culture}

Sheep skeletalmuscletissue was isolated from the longissimus dorsi muscles of sheep fetuses at gestational age of 80 days using the differential adhesion method. The tissues were digested with $5 \%$ Collagenase I for $30 \mathrm{~min}$ (Gibco, USA) with shaking and samples were then let stand for $5 \mathrm{~min}$.The upper cell suspension was removed and centrifuged at $1200 \mathrm{x} \mathrm{g} / \mathrm{min}$ for $5 \mathrm{~min}$. The supernatant was then removed, and Dulbecco's Modified Eagle Medium with Ham's F-12(DMEM/F12) medium (Gibco, USA) containing $10 \%$ fetal bovine serum (Gibco, USA) and 4\% penicillin-streptomycin-glutamine (Gibco, USA) was added. This sheep myoblast cell line was then initiated in medium containing $10 \%$ fetal bovine serum (Gibco, USA) under $5 \% \mathrm{CO}_{2}$ at $37 \stackrel{\circ}{-}$. To induce differentiation, Sheep fetal myoblast were seeded into $24-$ well plates, and after cells reached $80 \%$ confluence, DMEM containing $5 \%$ horse serum (Life Technologies, USA) was added differentiation medium. Plasmid DNAs were transfected into sheep fetal myoblasts using Lipofectamine ${ }^{\circledR} 3000$. (Life Technologies, USA).

\section{Quantitative Real-time quantitative PCR}

Total RNA from tissues or cells was extracted using TRIzol Reagent (Life Technologies, USA) according to the manufacturer's instructions. cDNA was synthesized from $2 \mu$ g total RNA using a PrimeScript ${ }^{\mathrm{TM}}$ RT Reagent Kit with gDNA Eraser (Takara, Japan). Primers used forquantitative real-time PCR (qRT-PCR) are listed in Table 1. The relative abundance of each mRNA analyzed was determined using SYBR Green Master Mix (Takara, Japan) with a CFX Connect ${ }^{\text {TM }}$ Real-time PCR Detection System (Bio-Rad, USA). Relative expression values were calculated using the comparative threshold cycle $(\Delta \Delta \mathrm{CT})$ method in accordance with the MIQE guidelines (PMID: 24173381). 


\section{Cellular Physiology Cell Physiol Biochem 2018;49:447-462 and Biochemistry \begin{tabular}{l|l} 
DOI: 10.1159/000492979 & $\begin{array}{l}\text { O 2018 The Author(s). Published by S. Karger AG, Basel } \\
\text { www.karger.com/cpb }\end{array}$
\end{tabular} \\ Wei et al.: Lnc-SEMT Enhances Sheep Muscularity}

\section{Cell transfection}

Transient transfection of cells with miRNA mimic, siRNA or DNA plasmids was performed in 24-well plates using Lipofectamine ${ }^{\circledR} \quad 3000$ reagent (Life Technologies, USA). For functional analyses of lnc-SEMT, the lnc-SEMT expression plasmid (500 ng) or empty plasmid (500 ng), plus the siRNA (100 nM) or control siRNA (100 nM) was transfected into cells in culture medium and then harvested for further analysis. For luciferase experiments, miRNA mimic (100 $\mathrm{nM})$ or miRNA inhibitor (100 nM) and psiCHECK-2 (500 ng) containing the wild type (WT) or mutated sequence of IncRNA-SEMT was transfected into cells. Cells were harvested to perform the dual-luciferase assay $24 \mathrm{~h}$ after transfection.

\section{Microinjection of zygotes and embryo transfer}

A plasmid containing the MEF2-myogenin promoter (a kind gift from Professor. Eric N. Olson, University of Texas Southwestern Medical Center) to drive lnc-SEMT expression in skeletal muscle was used to generate skeletal muscle-specific lnc-SEMT TG sheep. A total of 386 sheep zygotes were obtained by super-ovulation of females and artificial insemination. The zygotes were flushed from the oviducts using sterile filtered embryo flushing solution. After that, $4 \mathrm{pl} \mathrm{TE}$ solution containing $80 \mathrm{ng} / \mu \mathrm{L}$ of MEF2-myogeninpromoter-lnc-SEMTfragment was injected into the cytoplasm of 124 pronucleus embryos using injection needles. Injections were performed using an Eppendorf TransferMan NK2 micromanipulator (Eppendorf, German).A total of 105 embryos at the 2-to 4-cell stage were surgically transferred into 20 synchronized recipient ewes (5-6 embryos per recipient).Pregnancies were monitored by ultrasound scanning using a trans-abdominal linear probe every 2 weeks until days 90 . Nontransgenic control sheep were produced by normal sexual reproduction.

\section{Immunofluorescence staining}

Cells were fixed in 4\% paraformaldehyde for $15 \mathrm{~min}$ and permeabilized in $0.25 \%$ Triton X-100 for $10 \mathrm{~min}$ at room temperature. The cells were blocked in 1\% bovine serum albumin (BSA) for $30 \mathrm{~min}$ at room temperature and then incubated with1:200 primary antibody against Myosin Heavy Chain (MyHC) (Millipore, USA) at $4^{\circ} \mathrm{C}$ overnight with gentle shaking, followed by incubation with 1:100 FITC-conjugated secondary antibody (Cell Signaling Technology, USA) at room temperature for $1 \mathrm{~h}$, with thrice PBS washes after each antibody incubation. Nuclei were counter-stained with DAPI. The immunofluorescence images were visualized with a fluorescence microscope (Leica image analysis system, Germany).

\section{Immunoblotting}

Histological analyses were performed using a previously published method [36]. Briefly, frozen sections (7-8-mm thick) of gastrocnemius muscles were sectioned transversely, and paraffin-embedded sections of the muscle were subjected to histological analyses. Fibrosis staining was performed according to the published method [37] with slight modification. Briefly, paraffin sections of gastrocnemius were incubated with $5 \%$ BSA for $30 \mathrm{~min}$, with 1:100 primary antibodies against dystrophin (Abcam, UK) at $4^{\circ} \mathrm{C}$ overnight and then with1:100 FITC-conjugated secondary antibody (Cell Signaling Technology, USA) for 1 $\mathrm{h}$ at room temperature. For quantitative analyses of myofibers, 5 fields were randomly selected in stained sections. Myofibers were counted and divided by the total number of myofibers per the field. Images were visualized and captured with a fluorescence microscope (Leica image analysis system, Germany). 


\section{Cellular Physiology Cell Physiol Biochem 2018;49:447-462 \begin{tabular}{ll|l} 
DOI: 10.1159/000492979 & (0) 2018 The Author(s). Published by S. Karger AG, Basel \\
www.karger.com/cpb
\end{tabular}}

Wei et al.: Lnc-SEMT Enhances Sheep Muscularity

\section{Dual-luciferase assay}

WT Inc-SEMT or mutated lnc-SEMT were inserted into psiCHECK-2 (Promega, USA) at the 3' end of the coding sequence of Renilla luciferase, and constructs were then transfected into sheep fetal myoblasts. The activities of both luciferases were measured $24 \mathrm{~h}$ after transfection. Dual-luciferase assay were performed using the Double-Luciferase Reporter Assay Kit (Promega, USA). Cells were harvested and lysed with Cell Lysis Buffer. Renilla luciferase activity was normalized to the firefly luciferase activity.

\section{Biotin-labeled miR-125b capture}

Cells were harvested $24 \mathrm{~h}$ after transfection and then lysed on ice for $30 \mathrm{~min}$ in $250 \mu \mathrm{L}$ cell lysis buffer (10 mM KCl, $1.5 \mathrm{mM} \mathrm{MgCl}, 10 \mathrm{mM}$ Tris-Cl at pH 7.5, $5 \mathrm{mM} \mathrm{DTT}$ ) with RNasin (Takara, Japan) and proteinase inhibitor cocktail (Roche, USA). The supernatant was centrifuged for $5 \mathrm{~min}$ at $12,000 \times g$, and $\mathrm{NaCl}(1 \mathrm{M})$ and 30 $\mu \mathrm{L}$ beads (Dynabeads MyOne Streptavidin C1; Life Technologies, USA) were added. To ensure that the beads were RNase-free, they were washed 5 times with solution A $(0.1 \mathrm{M} \mathrm{NaOH}, 0.05 \mathrm{M} \mathrm{NaCl})$. The beads were then washed 3 times with $0.1 \mathrm{M} \mathrm{NaCl}$ and were blocked with $1 \mathrm{mg} / \mathrm{mL}$ BSA (Roche, USA) and $1 \mathrm{mg} /$ mL yeast tRNA (Ambion, USA) overnight before being mixed with the lysate. After rotating the beads and the lysate for $4 \mathrm{~h}$ at $4^{\circ} \mathrm{C}$, the beads were washed five times with washing buffer (5 mMTris-Cl, pH 7.5, 0.5 mM EDTA, $1 \mathrm{M} \mathrm{NaCl}$ ). RNA was extracted from the remaining beads with TRIzol Reagent (Life Technologies, USA) and evaluated using a One Step SYBR® PrimeScript ${ }^{\mathrm{TM}}$ RT-PCR Kit II (Takara, Japan). The entire PCR assay was performed in the same tomanner as the previous real-time qRT-PCR protocol described above.

\section{Anti-Ago2 immunoprecipitation}

Cells were harvested $48 \mathrm{~h}$ after transfection with the FLAG-Ago 2 vector. The cells were then lysed in 1 $\mathrm{mL}$ of lysis buffer (25 mM Tris-HCl, pH 7.4, $150 \mathrm{mM} \mathrm{NaCl}$ 0.5\% NP-40, $2 \mathrm{mM}$ EDTA, $1 \mathrm{mM} \mathrm{NaF}, 0.5 \mathrm{mM}$ DTT) with RNasin (Takara, Japan) and protease inhibitor cocktail (Roche, USA). The supernatant was centrifuged for $30 \mathrm{~min}$ at 12, $000 \times \mathrm{g}$, and then $30 \mu \mathrm{l}$ of anti-FLAG M2 magnetic beads were added (Sigma, USA). After rotating the beads with lysate for $4 \mathrm{~h}$ at $4^{\circ} \mathrm{C}$, the beads were washed thrice with washing buffer $(50 \mathrm{mM}$ Tris-HCl, $300 \mathrm{mM} \mathrm{NaCl}$, pH 7.4, $1 \mathrm{mM} \mathrm{MgCl2,} \mathrm{0.1 \%} \mathrm{NP-40).} \mathrm{The} \mathrm{RNA} \mathrm{was} \mathrm{extracted} \mathrm{from} \mathrm{the} \mathrm{remaining}$ beads with TRIzol Reagent (Life Technologies, USA) and evaluated using real-time PCR assay, which is the samemanner as the previous real-time qRT-PCR protocol described above.

\section{Western blotting}

For western blot analysis, total proteins were isolated from the muscle samples by homogenization in lysis buffer ( $50 \mathrm{mM}$ Tris- $\mathrm{HCl}, \mathrm{pH} 7.5,150 \mathrm{mM} \mathrm{NaCl}, 1 \%$ Triton X-100, $0.25 \%$ sodium deoxycholate, and complete protease inhibitor cocktail (AppliChem, Germany). The concentration of proteins was measured by Bradford reagent (Sigma, USA), separated on 10\% SDS-PAGE gels and transferred to PVDF membranes (Millipore, USA). After blocking in 5\% low-fat milk in PBST (0.1\% Tween 20 in PBS) for $1 \mathrm{~h}$ and incubated with primary antibody 1:1000 (Abcam, UK) or primary anti-Gapdh 1:2000 as control (Abcam, UK) at $4^{\circ} \mathrm{C}$ overnight. After 3 washing in PBST, the membranes were incubated in secondary antibody conjugated with horseradish peroxidase $(1: 5000)$ for $1 \mathrm{~h}$, followed by 3 washes in PBST. Antibody signals were detected by Novex ${ }^{\circledR}$ Chemiluminescent Substrates (Invitrogen, USA)

\section{Enzyme-linked immunosorbent assay for sheep Insulin-like growth factor 2}

To quantify IGF2 in cell supernatants or serum, an enzyme-linked immunosorbent assay (ELISA) was performed in microtiter plates coated with antibody recognizing IGF2 (Cusabio, USA). Samples were placed in a serum separator tube and allow samplesallowed to clot for two hours at room temperature or overnight at $4^{\circ} \mathrm{C}$ before centrifugation for $15 \mathrm{~min}$ at $1000 \times \mathrm{g}$. Remove serum and assay immediately or aliquot and store samples at $-80^{\circ} \mathrm{C}$. Avoid repeated freeze-thaw cycles. Add $100 \mu \mathrm{L}$ of standard and sample per well. Cover with the adhesive strip provided. Incubate for $2 \mathrm{~h}$ at $37^{\circ} \mathrm{C}$. Aspirate each well and wash, repeating the process two times for a total of three washes. Determine the optical density of each well within 5 min, using a microplate reader set to $450 \mathrm{~nm}$. 


\section{Cellular Physiology Cell Physiol Biochem 2018;49:447-462 \begin{tabular}{ll|l} 
and Biochemistry Published onlıne: 29August, 2018 & $\begin{array}{l}\text { (c) } 2018 \text { The Author(s). Published by S. Karger AG, Basel } \\
\text { www.karger.com/cpb }\end{array}$ \\
\hline
\end{tabular}

Statistical analysis

All numerical data are presented as mean \pm SD. Whenever necessary, statistical significance of the data was analyzed by performing one-sample $t$ tests, paired two-tailed $t$ tests, or one-way analysis of variance with Bonferroni's posttest SAS release 8.1 (SAS Institute Inc., Cary, NC). Significant differences between two groups were determined using Student's t test. $\mathrm{P}<0.05$ was considered statistically significant.

\section{Results}

Developmental changes in fetal sheep muscle

The differentiation and proliferation of muscle fibersin sheep occurs mainly at later stages of pregnancy. The potentialfor muscle growth depends on the muscle fibers number formed during the prenatal stage. In order to confirm the best time to analyze muscle proliferation and differentiation in embryo stage, five sheep fetus muscle with embryonic 75 days (-75), embryonic 90 days (-90), embryonic 105 days (-105) ,embryonic 120 days $(-120)$ and embryonic 135 days $(-135)$ were analyzed. As shown in Supplemental Fig. 1, the changes in longissimus dorsi fiber numbers and fiber density over time tend to increase before 120 days and then decrease (For all supplemental material see www.karger.com/ doi/10.1159/000492979). At the same time, the gastrocnemius muscle fiber numbers and fiber density were quickly increased from embryonic 90 days to embryonic 105 days (Supplemental Fig. 2). The longissimus dorsi cross-sectional area and gastrocnemius muscle increased throughout the whole embryo stage, but the biggest increasing was from embryonic 105 days to embryonic 120 days (Supplemental Fig. 3) which represents the most rapid period of muscle growth.

\section{Scan of the sheep genome for Inc-SEMT association}

Based on results of the above developmental analysis, two individual sheep fetuses at gestational ages of 90 days (-90) and 120 days (-120) were chosen for high-throughput sequencing to determine the roles of lncRNAs involved in sheep skeletal muscle generation. According to the result of the above, two sheep fetus with embryonic 90 days (-90) and embryonic 120 days $(-120)$ were selected for high-throughput sequencing. A total of 997.9 $\mathrm{M}$ reads was obtained and 8514 lncRNAs were assembled by Cufflinks (Fig. 1A). As the identification of transcripts involved immature mRNA fragments, we used four tools, namely Coding Potential Calculator (CPC), Pfam-scan (PFAM), phylogenetic codon substitution frequency (phyloCSF), Coding-Non-Coding-Index (CNCI) to remove potential coding transcripts from further analysis. Finally,1114 putative noncoding transcripts were retained and categorized as intergenic lncRNAs, intronic lncRNAs, anti-sense lncRNAs (Fig. 1A, B; Supplemental Fig. 4, 5). 791 contain only one exon (Supplemental Fig. 6). Given a false discovery rate (FDR) of $0.05 \%$ and q-value (P-adjusted) $<0.05$.IncRNA differentially expressed genes (DGEs) encoding IncRNAs were obtained from pairwise comparison of samples. To corroborate these putative lncRNAs, cDNA microarray analysis was performed to the conservations detect conserved and DGEs of differentially expressed lncRNAs. Of the 1114 lncRNAs, 446 lncRNAs were differentially expressed, among these, 157 lncRNAs expressed was higher relative to controls (Fig. 1C; Supplemental Table S1 and Supplemental Fig. 7). One 750-bp lncRNA, designated lnc-SEMT (for sheep skeletal enhanced muscularity transcript) (Supplemental Table S2) was found to be specifically highly expressed in skeletal muscle (Fig. 1D).The expression of lnc-SEMT in different types of muscle including semitendinosus, gastrocnemius, quadriceps muscle, gastric smooth muscle. Our results showed lnc-SEMT to be expressed with high specificity in skeletal muscle tissue and also especially highly expressed in the semitendinosus, gastrocnemius and longissimus dorsi (Fig. 1C; Supplemental Table S1 and Fig. 1D). Bioinformatics analysis suggested that lncSEMT does not have protein-coding potential (Fig. 1E). Real-time PCR data showed that expression of lnc-SEMT was up regulated during sheep myoblast differentiation as did the abundances of Myog and Myod transcripts (Fig. 1F and Fig. 1G). 


\section{Cellular Physiology Cell Physiol Biochem 2018;49:447-462 \begin{tabular}{ll|l} 
DOI: 10.1159/000492979 & $\begin{array}{l}\text { O } 2018 \text { The Author(s). Published by S. Karger AG, Basel } \\
\text { www.karger.com/cpb }\end{array}$ \\
\hline and Biochemistry
\end{tabular}

\section{Inc-SEMT accelerates myoblast differentiation in vitro}

To investigate the role of lnc-SEMT during myogenesis in vitro, we used RNA interference (RNAi) to knockdown lnc-SEMT expression and an expression vector to overexpress lnc-SEMT in sheep myoblasts. Successful knockdown of lnc-SEMT (Fig. 2A) resulted in significant inhibition of myoblast differentiation as assessed by the reduced Myosin Heavy Chain (MyHC) immunostaining (Fig. 2B), decreased number of positive myotubes (Fig. 2C) and down regulated expression of myogenic marker genes Myod and Myog (Fig. 2D). Moreover, overexpression of lnc-SEMT (Fig. 2E) accelerated the differentiation of myoblast with increased MyHC immunostaining (Fig. 2F), increased myotube numbers (Fig. 2G), and upregulated Myod and Myog expression (Fig. 2H).

\section{Muscle specific Inc-SEMTexpression in transgenic TG sheep with enhanced muscularity in} vivo

To determine the in vivo function of lnc-SEMT during myogenesis, we established a small population of TG sheep expressing lnc-SEMT in a skeletal muscle-specific manner, as shown in Fig. 3A. Out of 124 embryos injected embryos with the lnc-SEMT construct, 105 healthy embryos were transferred into surrogate mothers, and 22 lambs were born (T02, T06, T11, T13, T18, Supplemental Table S3). Of these 22 lambs, 5 were confirmed as lnc-SEMT positive

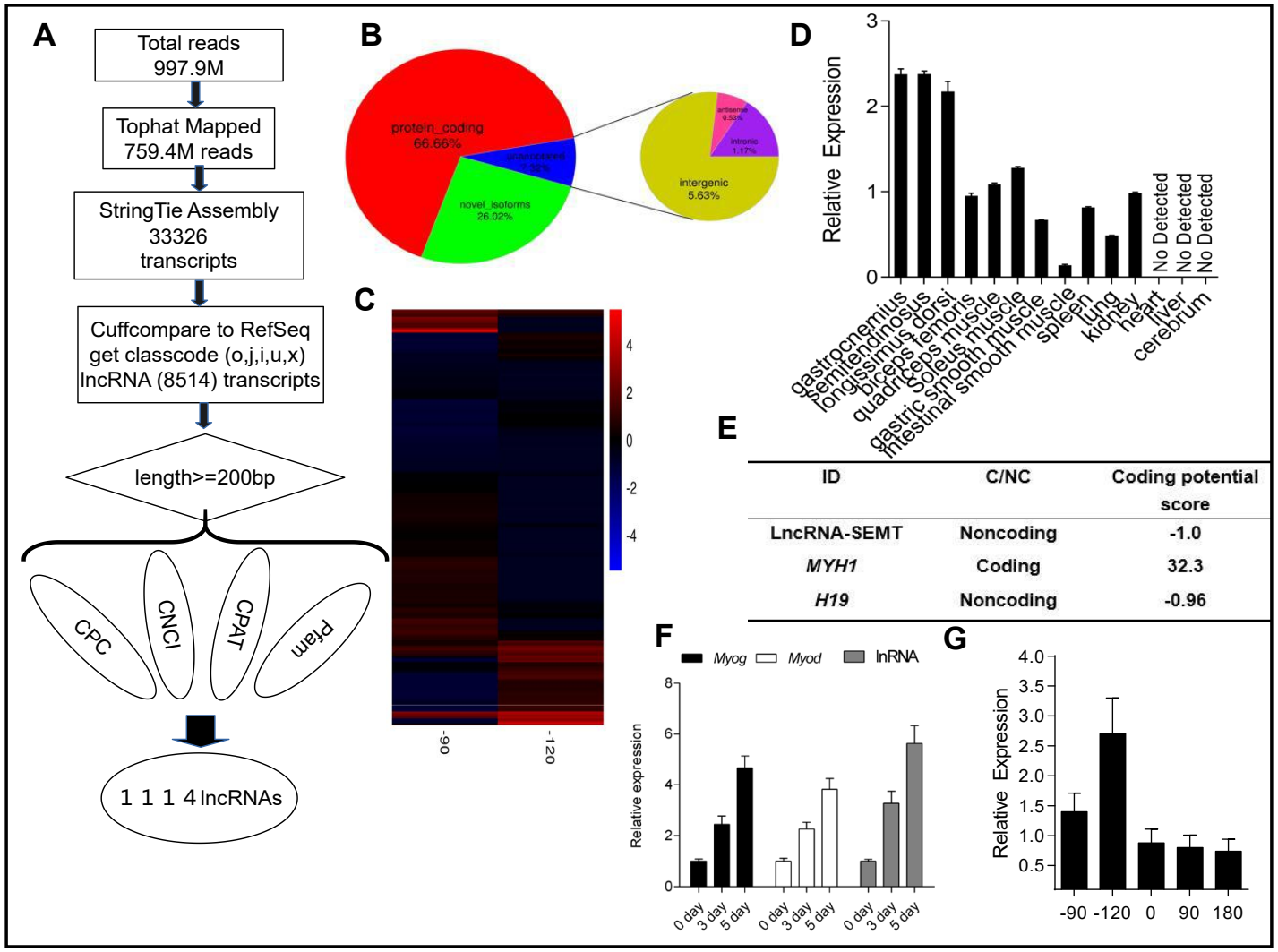

Fig. 1. Scan of the sheep genome for lnc-SEMT associations. (A) Workflow of RNA-seq. (B) lncRNAs divide into the intergenic lncRNAs, intronic lncRNAs and anti-sense lncRNAs. (C) Heatmap of microarray analysis was implemented to corroborate putative IncRNAs. (D) Real-time PCR analysis of Inc-SEMT expression in heart, liver, spleen, lung, cerebrum, brain and several types of sheep muscles. Mean values \pm SEM, $n=3, *$ $\mathrm{P}<0.05$.(E) The protein-coding potential of Inc-SEMT by Bioinformatics analysis.(F) Real-time PCR analysis of lnc-SEMT expression in sheep myoblasts at undifferentiated stage (0 days), differentiated stage (3 days and 5days). Mean values \pm SEM, $n=3, * P<0.05$. (G)Real-time PCR analysis of Inc-SEMT expression in sheep longissimus dorsi at embryonic 90 days (-90) and embryonic 120 days (-120), new born (0), postnatal 90 days (90) and postnatal 180 days (180). Mean values \pm SEM, $n=3, * \mathrm{P}<0.05$. 


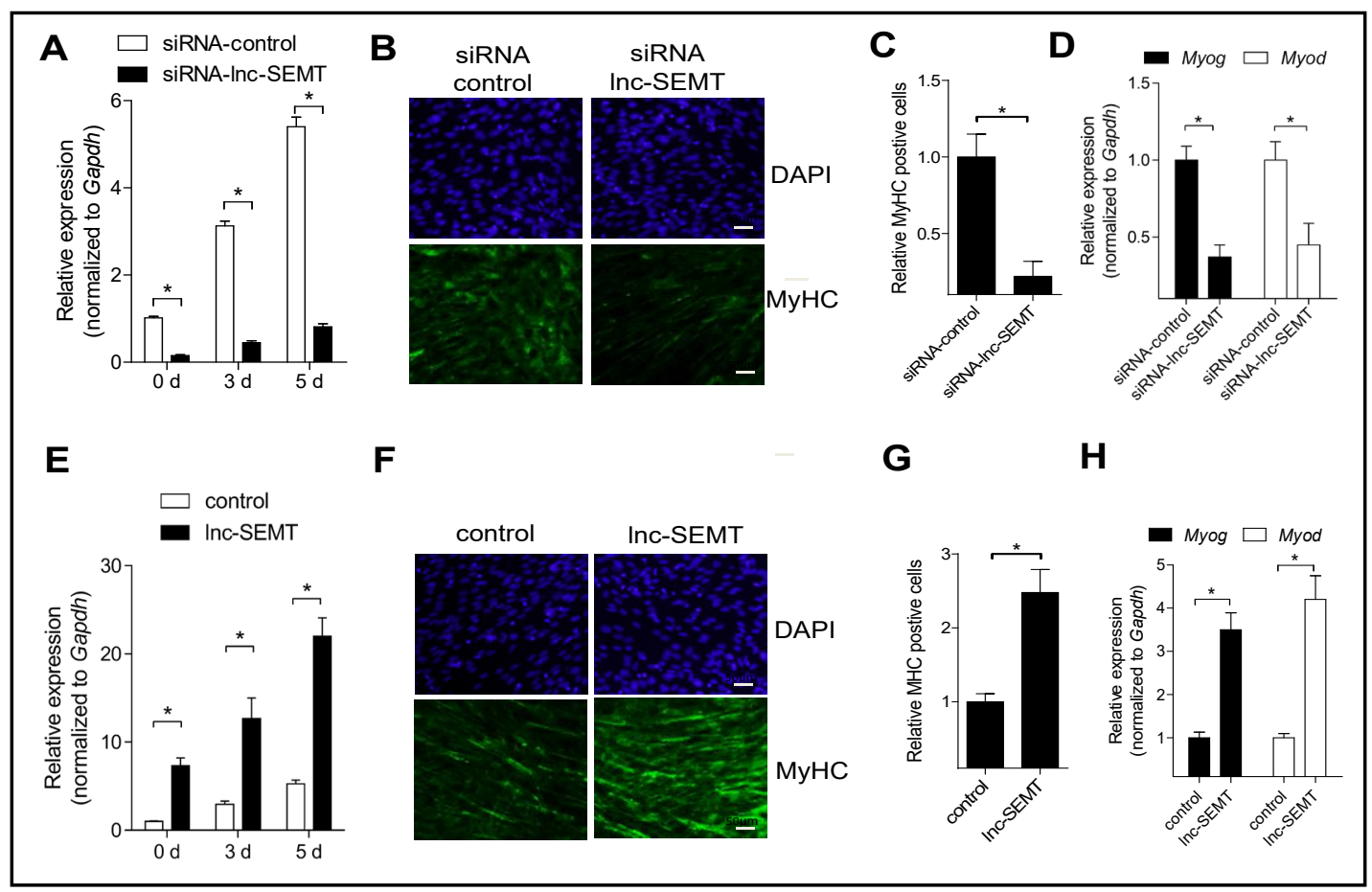

Fig. 2. Inc-SEMT accelerates myoblast differentiation in vitro. (A) Real-time PCR analysis of lnc-SEMT expression in sheep myoblasts transfected with control siRNA or lnc-SEMT siRNA. (B) MyHC immunostaining of myoblasts transfected with control siRNA or Inc-SEMT siRNA then cultured in differentiation medium for 5 d. Scale bar: $50 \mu \mathrm{m}$. (C) Relative MyHC positive myoblasts for Fig. b. (D) Real-time PCR analysis of MyoG and MyoD expression in myoblasts transfected with control siRNA or lnc-SEMT siRNA then cultured in differentiation medium for $5 \mathrm{~d}$. (E) Real-time PCR analysis of lnc-SEMT expression in myoblasts transfected with control vector or Inc-SEMT vector. (F) MyHC immunostaining of myoblasts transfected with control vector or lnc-SEMT vector then cultured in differentiation medium for $5 \mathrm{~d}$. Scale bar: $50 \mu \mathrm{m}$. (G) Relative MyHC positive cells transfected with control vector or lnc-SEMT vector then cultured in differentiation medium for $5 \mathrm{~d}$. (H) Real-time PCR analysis of Myod and Myog expression in myoblasts transfected with control vector or lnc-SEMT vector then cultured in differentiation medium for $5 \mathrm{~d}$. All data are shown as mean values $\pm S E M, n=3, * P<0.05$.

TG sheep using Real-time PCR analysis. (Fig. 3B). The body weights of TG sheep increased faster than those of control WT sheep during the 9 months after birth (Fig. 3C). The 6-monthold TG sheep (48.25 kg) was heavier than WT sheep (38.72 kg) (Fig. 3D). Daily weight gain of WT sheep was $0.24 \mathrm{~kg} / \mathrm{d}$, when compared with $0.17 \mathrm{~kg} / \mathrm{d}$ for control WT sheep (Fig. 3E).

Slaughter weight of TG sheep was 27.6kg (T13), compared with $20.8 \mathrm{~kg}$ for WT sheep (Fig. 4A). The sizes of several different types of skeletal muscles in the TG and WT sheep were measured and compared (Fig. 4B-Fig. 4F). Several skeletal muscles of the TG sheep were visibly larger than those of WT sheep. The number of muscle fibers per muscle section was also greater in TG sheep compared with WT sheep determined histologically on hematoxylin and eosin (H\&E) and immunohistochemical staining (Fig. 4F, G, H and I).

\section{Knockdown of Inc-SEMT inhibited muscle growth in vitro}

In order to determine the effect knock-down of lnc-SEMT on sheep muscle, we used RNA interference (RNAi) to knockdown lnc-SEMT in the gastrocnemius muscle of left rear leg of a 1-month-old lamb;the gastrocnemius muscle of the right rear leg served as control muscle. Inc-SMET knockdown sheep gastrocnemius muscle showed inhibition of growth in gastrocnemius muscle weight compared with control WT sheep gastrocnemius muscle (Fig. $5 \mathrm{~A}$ ). There were also fewer muscle fibers in lnc-SMET knock-down sheep compared with 


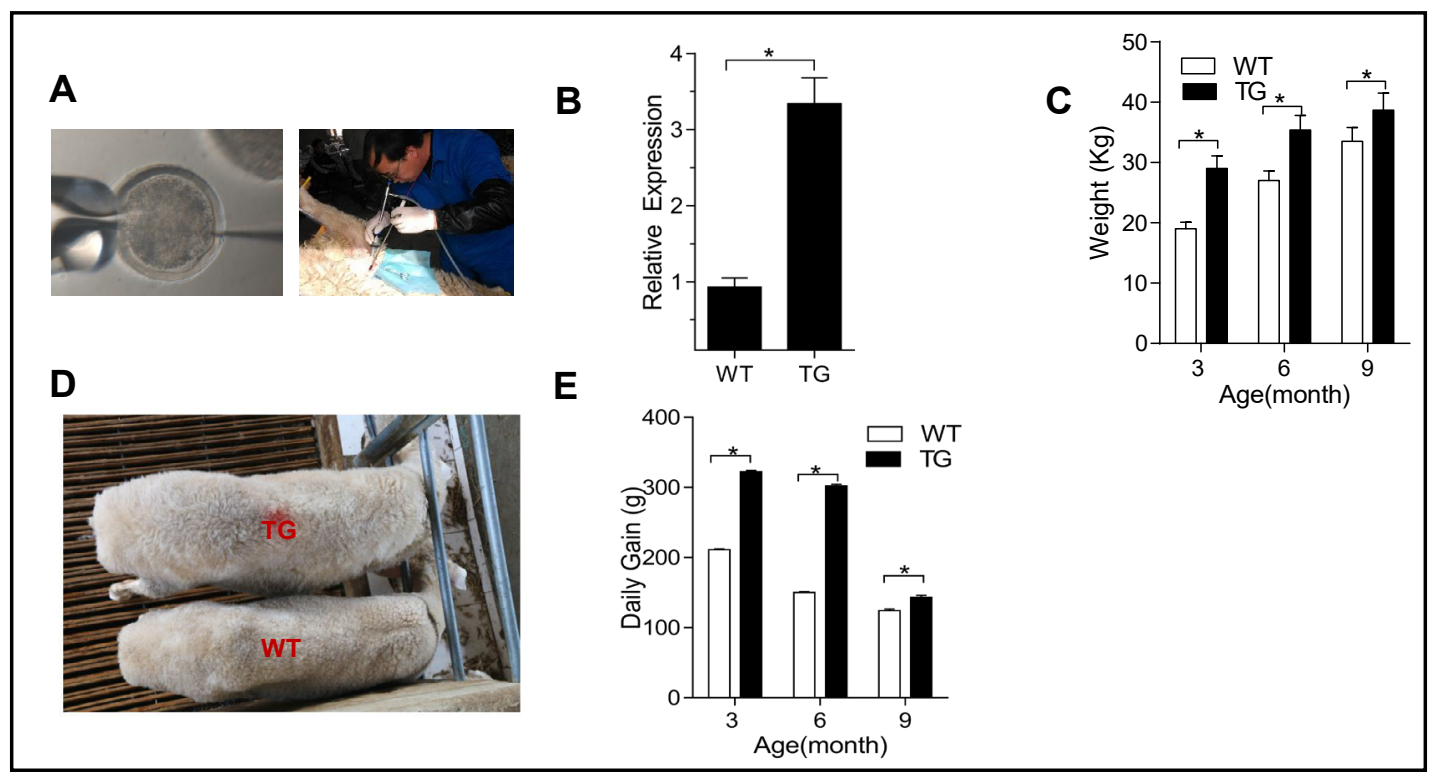

Fig. 3. Muscle specific lnc-SEMT TG sheep with enhanced muscularity. (A) The TG sheep obtained by injection of zygotes and intrauterine cervical insemination. (B) Real-time PCR analysis of lnc-SEMT expression in longissimus dorsi from WT and TG sheep. (C) Body weight of the WT and TG sheep at 3, 6 and 9 months postpartum. (D) RepresentativeTG sheep and WT sheep at 6 months postpartum. (E) Daily Gain of the WT and TG sheep at 3, 6 and 9 months postpartum. All data are shown as mean values $\pm S E M, n=5,{ }^{*} P<0.05$.

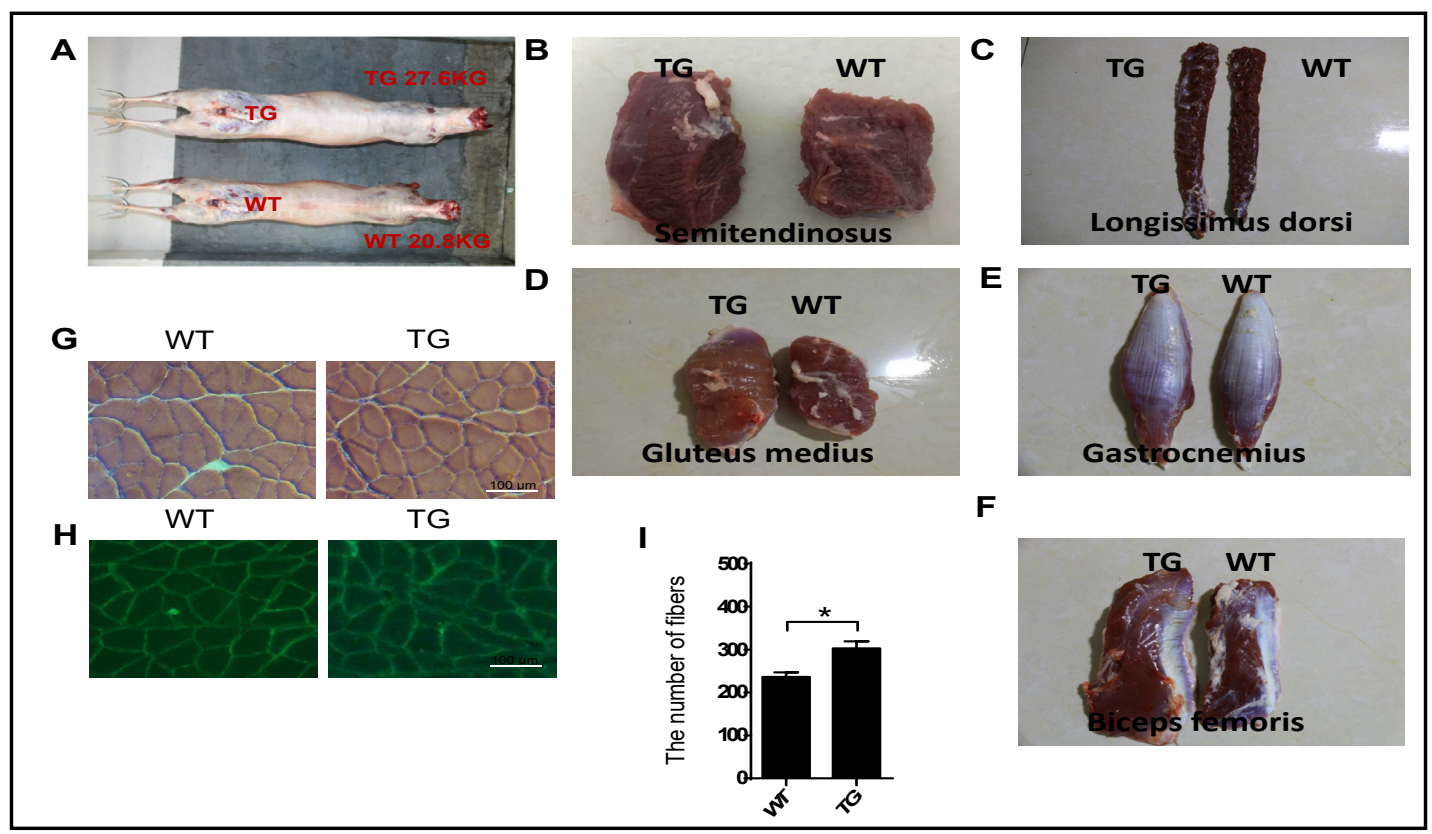

Fig. 4. (A) The representative Fig.s of TG sheep and WT sheep after the slaughter at 6 months postpartum. (B) The size of semitendinosus between the transgenic sheep and wild type sheep. (C) The sizes of longissimus dorsi between the transgenic sheep and wild type sheep. (D) The sizes of gluteus medius between the transgenic sheep and wild type sheep. (E) The sizes of gastrocnemius between the transgenic sheep and wild type sheep. (F) The sizes of biceps femoris between the transgenic sheep and wild type sheep. (G) Histological cross section of longissimus dorsi from WT sheep and TG sheep. (H) Immunostaining of dystrophin from longissimus dorsi for WT and lnc-SEMT TG sheep at 6 months postpartum. Scale bar = $100 \mu \mathrm{m}$. (I) Distribution of muscle fiber sizes in WT and TG sheep. A total of 500 fibers from each image were measured. 


\section{Cellular Physiology Cell Physiol Biochem 2018;49:447-462 and Biochemistry \begin{tabular}{c|c} 
DOI: 10.1159/000492979 & $\begin{array}{l}\text { O 2018 The Author(s). Published by S. Karger AG, Basel } \\
\text { www.karger.com/cpb }\end{array}$
\end{tabular}

control WT sheep, as determined by $\mathrm{H} \& \mathrm{E}$ staining and scanning electronmicroscopy (Fig. 5B, C).Also, the qRT-PCR results indicated that the expression of lnc-SEMT in gastrocnemius muscleof lnc-SMET knockdown sheep were significantly lower than in the gastrocnemius muscle of control WT sheep (Fig. 5D). Finally, the expression of both Myod and Myog transcripts were relatively lower in gastrocnemius muscle of lnc-SMET knockdown sheep compared with gastrocnemius muscle of control WT sheep (Fig. 5E and F).

Lnc-SEMT binds to miR$125 \mathrm{~b}$ to function as miRNA sponge

Because IncRNA function as competing ceRNAs that compete with mRNAs for target miRNAs [36, 38, 39], we used bioinformatics analysis to identifya potential miR$125 \mathrm{~b}$ binding site on lnc-SEMT.

To verify whether lnc-SEMT is indeed targeted by miR-125b, WT and mutant miR-125b were synthesized (Fig. 6A), and luciferase reporters containing a WT or mutant target site from lnc-SEMT were also constructed (Fig. 6B). Only wild type miR-125b (AgomiR-125b) significantly reduced luciferase activity for the WT Inc-SEMT reporter (Fig. 6C), and only WT lnc-SEMT was recognized by AgomiR-125b (Fig. 6D). Moreover, to determine whether lncSEMT antagonizes other miR-125 family members. We detected the expression of miR-125a and miR-125b in different tissues of sheep (Fig. 6E), the results showed that both miR-125a and miR-125b are highly expressed in several tissues of sheep including lung, heart, spleen, kidney, liver. But the expression of miR-125a was significantly lower than miR-125b in skeletal muscle of sheep (Fig. 6F). Therefore, the ability of miR-125b binding lnc-SEMTwas tested. Furthermore, the luciferase activity of WT Inc-SEMT reporter specifically increased upon a decrease in endogenous miR-125b levels due to Antagomir-125b expression (Fig. $6 \mathrm{G}, \mathrm{H})$. As added evidence supporting the ceRNA function of lnc-SEMT immunoprecipitation of Ago 2 and capture of biotin-labeled miR-125b followed by Real-time PCR confirmed the interaction between miR-125b and lnc-SEMT (Fig. 6I, J).

Luciferase reporters expressing IGF2, were transfectedtogether with either WT or mutant lnc-SMET into myoblasts, and when WT Inc-SEMT was transfected into the myoblasts, IGF2 activity increased. Meanwhile, biotin-labeled miR-125b, IGF2, WT and mutant lncSEMT were also transfected into the myoblasts to determine the function of miR-125b.When WT lnc-SEMT was transfected into myoblasts,binding of IGF2 with biotin-labeled miR-125b was clearly down-regulated. Collectively, these observations show that lnc-SEMTbinds with miR-125b in competition with IGF2 to negatively modulate myoblast differentiation in vitro (Fig. 7A, B). 


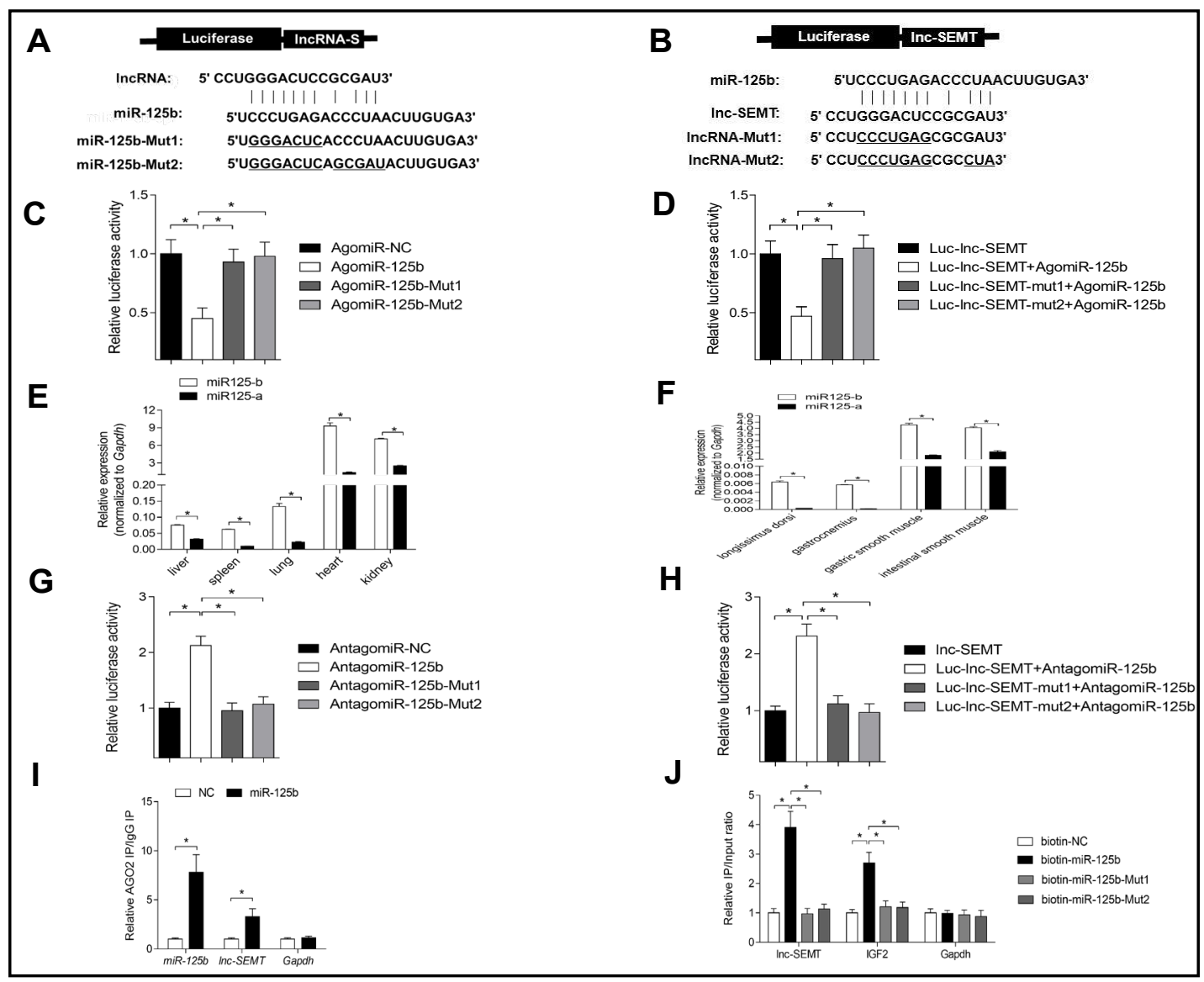

Fig. 6. Inc-SEMT acts as a molecular sponge for miR-125b in vitro. (A) Potential binding sites in lnc-SEMT and miR-125b.Two seed sequence mutants of miR-125b (miR-125b-mut1 and miR-125b-mut2) are shown below. The underlined sequences represent the mutant site. (B) Luciferase reporter constructs: wild type lnc-SEMT and two lnc-SEMT mutants (lnc-SEMT-mut1 and lnc-SEMT-mut2) in the miR-125b binding site were inserted into psiCHECK-2 vector. The underlined sequences represent the mutant sites. (C) The relative luciferase activity of psiCHECK-2 containing WT lnc-SEMT co-transfected with AgomiR-125b or mutated AgomiR-125b. (D) The relative luciferase activity of psiCHECK-2 expressing WT or mutated lnc-SEMT cotransfected with AgomiR-125b. (E) Real-time PCR analysis of miR-125b and miR-125a expression in the different tissues of the sheep. (F) Real-time PCR analysis of miR-125b and miR-125a expression in muscle of the sheep.(G) The relative luciferase activity of psiCHECK-2 containing WT Inc-SEMT co-transfected with Antagomir-125b or mutated Antagomir-125b. (H) The relative luciferase activity of psiCHECK-2 expressing WT or mutated lnc-SEMT co-transfected with Antagomir-125b. (I) Ago2 immunoprecipitation was performed in sheep myoblasts transfected with control miRNA (miR-NC) or miR-125b, followed by real-time PCR to detect Inc-SEMT associated with Ago2. (J) Streptavidin capture was performed in sheep myoblasts transfected with biotin-miR-NC, biotin-miR-125b or mutated biotin-miR-125b, followed by realtime PCR to detect lnc-SEMT, IGF2 mRNA and control Gapdh mRNA abundances.

\section{Inc-SEMT regulates the expression of IGF2}

Importantly, the abundance of IGF2, a critical target gene of miR-125b during myogenesis, decreased upon lnc-SEMT knockdown and upregulated by lnc-SEMT overexpression, as shown by western blotting (Fig. 8A, B). The ability of Inc-SEMT to modulate levels of secreted IGF2 protein in myoblast supernatants was further verified by ELISA (Fig. 8C, D). We also found that when IGF2 was knocked down in vitro, lnc-SEMT abundance decreased (Fig. 8E, F). We also showed that knockdown of IGF2 suppressed lnc-SEMT induced myoblast fusion (Supplemental Fig. 8), and knockdown of IGF2 suppressed lnc-SEMT induced myogenic 


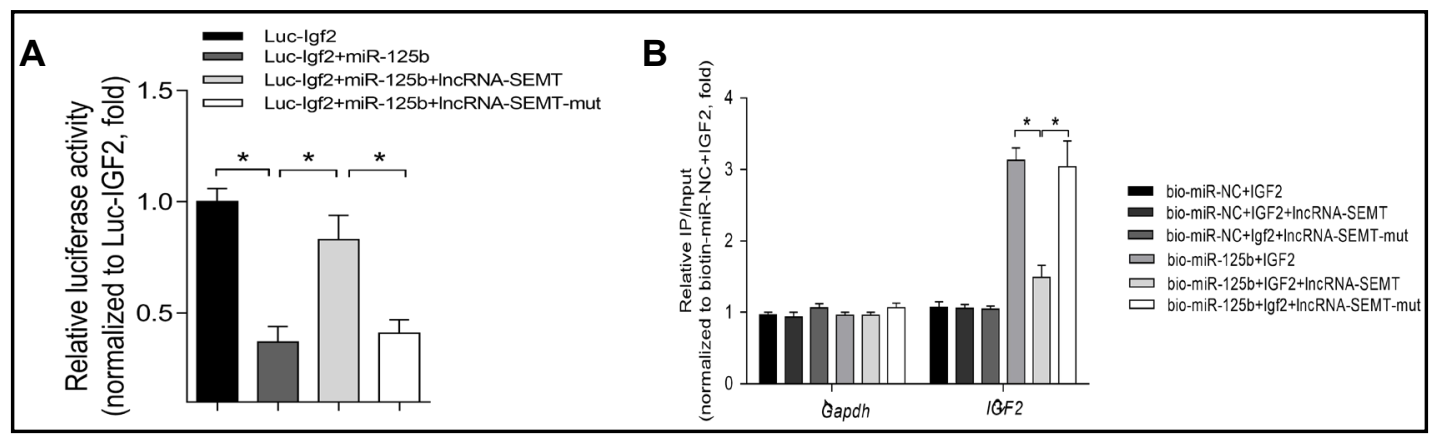

Fig. 7. (A) The relative luciferase activity of psiCHECK-2 expressing IGF2 3'UTR co-transfected with miR125b, miR-125b and lncRNA-SEMT, miR-125b and mutated IncRNA-SEMT respectively in sheep myoblasts. Mean values \pm SEM, $n=3,{ }^{*} \mathrm{P}<0.05$. (B) Streptavidin capture was performed in extracts of sheep myoblasts co-transfected with biotin-miR-NC or biotin-miR-125b and IGF2 3'UTR, IGF2 3'UTR together with IncRNASEMT or IGF2 3'UTR together with IncRNA-SEMT-mut, followed by Real-time PCR to detect IGF2 mRNA and control Gapdh mRNA abundances. Mean values $\pm \mathrm{SEM}, \mathrm{n}=3,{ }^{*} \mathrm{P}<0.05$.

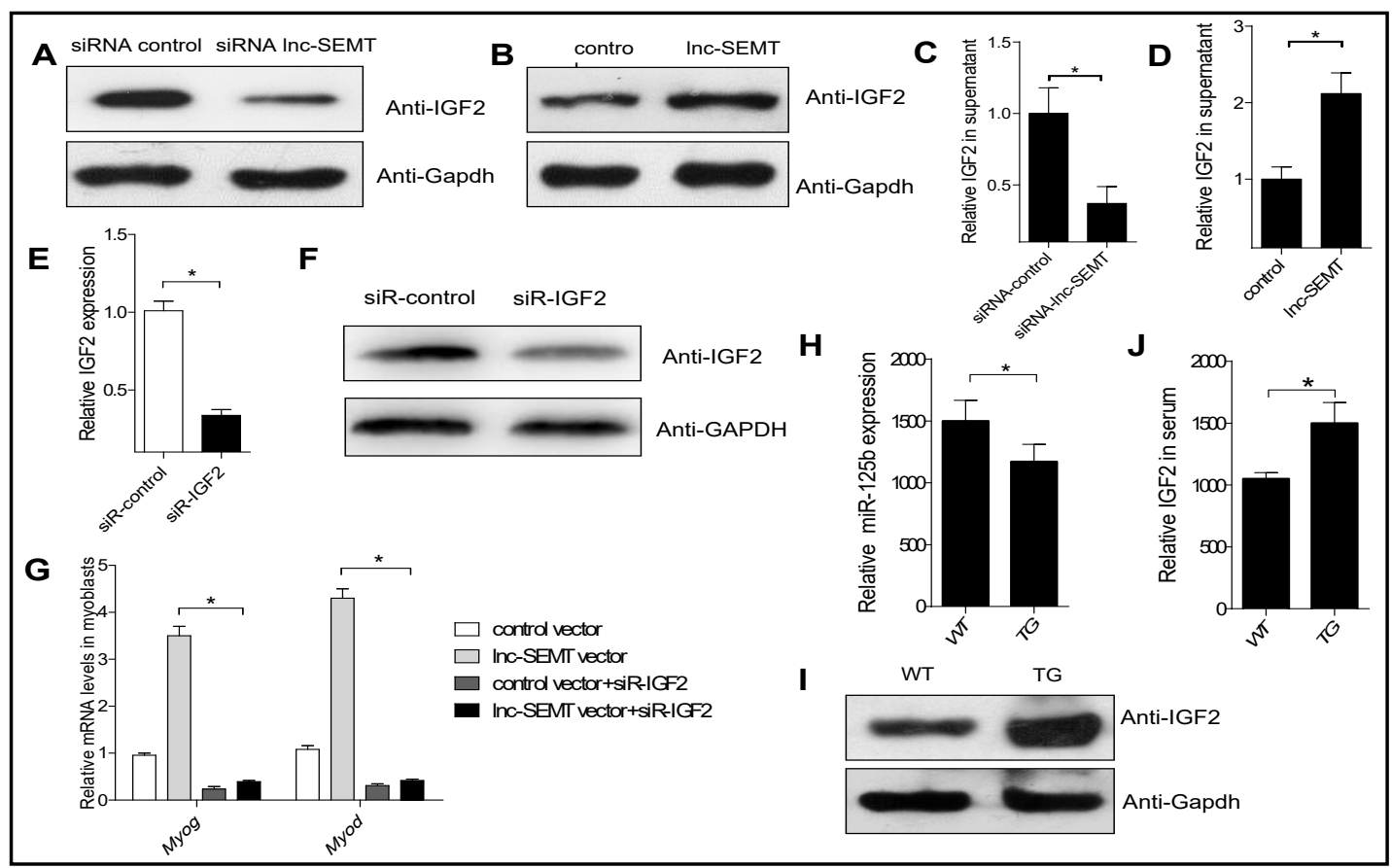

Fig. 8. Inc-SEMT regulates the expression of IGF2. (A) Western blot analysis of IGF2 protein abundances in sheep myoblasts transfected with control siRNA or lnc-SEMT siRNA. (B) Western blot analysis of IGF2 protein abundances in sheep myoblasts transfected with control vector or lnc-SEMT vector. (C) ELISA analysis of secreted IGF2 protein abundances in supernatant from sheep myoblasts transfected with control siRNA or lnc-SEMT siRNA. (D) ELISA analysis of secreted IGF2 protein levels in supernatant from sheep myoblasts transfected with control vector or lnc-SEMT vector. Mean values $\pm \mathrm{SEM}, \mathrm{n}=3, * \mathrm{P}<0.05$.(E)Realtime PCR analysis of IGF2 expression levels in sheep myoblasts transfected with control siRNA or IGF2 siRNA. Mean values \pm SEM, $n=5, * P<0.05$. (F) Western blot analysis of IGF2 protein levels in sheep myoblasts transfected with control siRNA or IGF2 siRNA. (G)Real-time PCR analysis of expression of myogenic gene in sheep myoblasts transfected with control vector or lnc-SEMT vector or control vector with IGF2 siRNA or lnc-SEMT vector with IGF2 siRNA. (H) Real-time PCR analysis of miR-125b expression in longissimus dorsi musclefrom WT and TG sheep. Mean values $\pm \mathrm{SEM}, \mathrm{n}=5, * \mathrm{P}<0.05$. (I) Western blot analysis of IGF2 protein abundances in longissimus dorsimuscle from WT and TG sheep. (J) ELISA analysis of IGF2 protein abundances in serum from WT and TG sheep. Mean values \pm SEM, $n=5, * 2<0.05$.

\section{KARGER}


gene expression (Fig. 8G). To determine whether lncSEMT antagonizes miR$125 \mathrm{~b}$ in vivo, we observed that miR-125b abundances were lower and the IGF2 protein abundances were higher in longissimus dorsi and serum from lnc-SEMT TG sheep compared to WT sheep (Fig. 8H, I). In addition to defined IncRNASEMT whether involved the muscle differentiation by binding with miR-125b in competition with IGF2, we observed that the IGF2

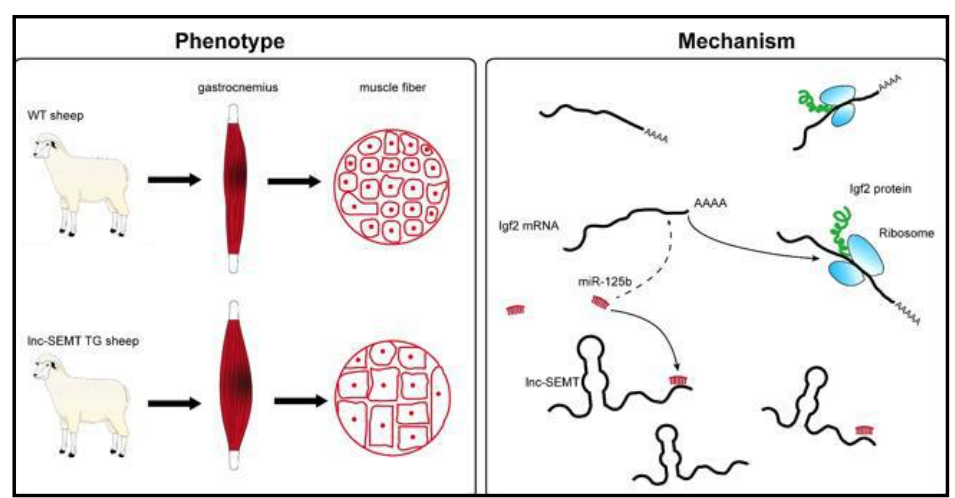

Fig. 9. Model for promotion of myogenesis by lnc-SMET in vitro and enhancement of muscularity by lnc-SMET in vivo. Overexpression of the skeletal muscle-enriched lncRNA, lnc-SMET, antagonizes miR-125b to control IGF2 protein level and enhance muscularity in sheep. protein abundances were higher in serum from lnc-SEMT TG sheep than in WT sheep (Fig. 8J).

Taken together, our results indicate that we identified a sheep skeletal muscle-enriched lncRNA, that promotes myoblast differentiation both in vitro and in vivo. By acting as a molecular sponge, lnc-SEMTantagonizes miR-125b to control IGF2 protein abundance. These RNAs could serve as useful candidates for improving muscle production in sheep (Fig. 9).

\section{Discussion}

The number of muscle fibers is nearly complete before birth [40, 41], and postnatal muscle growth is mainly due to increases inmuscle fiber diameter, cross-sectional area and increased muscle mass. Therefore, we chose the muscle samples from fetal sheep as the system in which to define prenatal developmental changes in sheep muscle. The central role of miRNAs in skeletal muscle development has been demonstrated by the detrimental consequences of Dicer deletion in embryonic skeletal muscle [42-44]. RNA-Seq technology has allowed the discovery and analysis of noncoding RNAs, and differential methods have been developed to identify novel lncRNAs in RNA-Seq data $[45,46]$. Although many studies have highlighted the important roles of IncRNAs indifferent tissues $[47,48]$, little is known about the biological function and significance of IncRNAsduring skeletal muscle development in sheep. High-throughput sequencing was performed using two sheep fetuses at gestational ages of 90 days and 120 days to identify lncRNAs affecting the rapidly increase in muscle fiber number and muscle cross-sectional area during this period. Earlier investigations of vertebrate muscle development led to the discovery of transcription factors (MYOD1, MYF5, and $M Y O G$ ) and chromatin modifiers as key regulators of muscle specification [49-52]. Advancement in muscle specification research has been stimulated by the identification of regulatory small noncoding RNAs andlncRNAs as critical orchestrators of muscle specification $[53,54]$. Therefore, we attempted to identify lncRNA molecules that could promote progress muscle development and growth in sheep.

In this study, we established skeletal muscle-specific transgenic knock out sheep, but we could not obtain the TG knock-out sheep for technical reasons. Therefore, we carried out this lnc-SMET knockout experiment on lambs as a model for muscle development and growth. Muscle differentiation is a powerful system for these investigations, because it can be both recapitulated in vitro and because the networks of transcription factors coordinating the expression of genes involved in muscle growth, morphogenesis, and differentiation are well known and evolutionarily conserved [22]. Moreover, recent studies have shown that these myogenic transcription factors not only control protein-coding genes but also regulate the 


\section{Cellular Physiology Cell Physiol Biochem 2018;49:447-462 \begin{tabular}{ll|l} 
DOI: 10.1159/000492979 & $\begin{array}{l}\text { O } 2018 \text { The Author(s). Published by S. Karger AG, Basel } \\
\text { www.karger.com/cpb }\end{array}$ \\
\hline and Biochemistry
\end{tabular} \\ Wei et al.: Lnc-SEMT Enhances Sheep Muscularity}

expression of specific miRNAs $[55,56]$. Those earlier results are consistent with our current research, which indicates lnc-SEMT can interact with miR-125b to control the expression of IGF2 during skeletal muscle generation.

\section{Conclusion}

Here, we have identified a sheep skeletal muscle-enriched lncRNA,Inc-SMET, which can enhance muscle differentiation in sheep.To our knowledge,this is the first study to provide a comprehensive functional and mechanistic in vivo characterization of a specific lncRNA during sheep muscle differentiation. Our model is that lnc-SMET actsas a molecular sponge, and antagonizes miR-125b to control IGF2 protein abundance. These genes might serve as useful candidates for improving muscle production in sheep.

\section{Acknowledgements}

This work was supported by National Natural Science Foundation Projects (31672380).

\section{Disclosure Statement}

The authors of this manuscript state that they have no conflicts of interest to declare.

\section{References}

1 Du M, Zhu MJ, Means WJ, Hess BW, Ford SP: Effect of nutrient restriction on calpain and calpastatin content of skeletal muscle from cows and fetuses. J Anim Sci 2004;82:2541-2547.

-2 Zhu MJ, Ford SP, Nathanielsz PW, Du M: Effect of maternal nutrient restriction in sheep on the development of fetal skeletal muscle. Biol Reprod 2004;71:1968-1973.

-3 Du M, Zhu MJ, Means WJ, Hess BW, Ford SP: Nutrient restriction differentially modulates the mammalian target of rapamycin signaling and the ubiquitin-proteasome system in skeletal muscle of cows and their fetuses. J Anim Sci 2005;83:117-123.

4 McCoard SA, McNabb WC, Peterson SW, McCutcheon SN, Harris PM: Muscle growth, cell number, type and morphometry in single and twin fetal lambs during mid to late gestation. Reprod Fertil Dev 2000;12:319327.

5 Chen X: Small RNAs and their roles in plant development. Annu Rev Cell Dev Biol 2009;25:21-44.

-6 Ulitsky I, Shkumatava A, Jan CH, Sive H, Bartel DP: Conserved function of lincRNAs in vertebrate embryonic development despite rapid sequence evolution. Cell 2011;147:1537-1550.

7 Ulitsky I, Bartel DP: lincRNAs: genomics, evolution, and mechanisms. Cell 2013;154:26-46.

-8 Zhang YC, Liao JY, Li ZY, Yu Y, Zhang JP, Li QF, Qu LH, Shu WS, Chen YQ: Genome-wide screening and functional analysis identify a large number of long noncoding RNAs involved in the sexual reproduction of rice. Genome Biol 2014;15:512.

-9 Cabili MN, Trapnell C, Goff L, Koziol M, Tazon-Vega B, Regev A, Rinn JL: Integrative annotation of human large intergenic noncoding RNAs reveals global properties and specific subclasses. Genes Dev 2011;25:1915-1927.

-10 Li L, Eichten SR, Shimizu R, Petsch K, Yeh CT, Wu W, Chettoor AM, Givan SA, Cole RA, Fowler JE, Evans MM, Scanlon MJ, Yu J, Schnable PS, Timmermans MC, Springer NM, Muehlbauer GJ: Genome-wide discovery and characterization of maize long non-coding RNAs. Genome Biol 2014;15:R40.

11 Mattick JS: The central role of RNA in human development and cognition. FEBS Lett 2011;585:1600-1616.

12 Nagano T, Fraser P: No-nonsense functions for long noncoding RNAs. Cell 2011;145:178-181.

13 Wang KC, Chang HY: Molecular mechanisms of long noncoding RNAs. Mol Cell 2011;43:904-914.

14 Wapinski O, Chang HY: Long noncoding RNAs and human disease. Trends Cell Biol 2011;21:354-361. 


\section{Cellular Physiology Cell Physiol Biochem 2018;49:447-462 \begin{tabular}{ll|l} 
DOI: 10.1159/000492979 & $\begin{array}{l}\text { O 2018 The Author(s). Published by S. Karger AG, Basel } \\
\text { www.karger.com/cpb }\end{array}$ \\
\hline
\end{tabular}

15 Ma W, Ay F, Lee C, Gulsoy G, Deng X, Cook S, Hesson J, Cavanaugh C, Ware CB, Krumm A, Shendure J, Blau CA, Disteche CM, Noble WS, Duan Z: Fine-scale chromatin interaction maps reveal the cis-regulatory landscape of human lincRNA genes. Nat Methods 2015;12:71-78.

16 Beltran M, Puig I, Pena C, Garcia JM, Alvarez AB, Pena R, Bonilla F, de Herreros AG: A natural antisense transcript regulates Zeb2/Sip1 gene expression during Snail1-induced epithelial-mesenchymal transition. Genes Dev 2008;22:756-769.

-17 Tripathi V, Ellis JD, Shen Z, Song DY, Pan Q, Watt AT, Freier SM, Bennett CF, Sharma A, Bubulya PA, Blencowe BJ, Prasanth SG, Prasanth KV: The nuclear-retained noncoding RNA MALAT1 regulates alternative splicing by modulating SR splicing factor phosphorylation. Mol Cell 2010;39:925-938.

$>18$ Chen L, Feng P, Zhu X, He S, Duan J, Zhou D: Long non-coding RNA Malat1 promotes neurite outgrowth through activation of ERK/MAPK signalling pathway in N2a cells. J Cell Mol Med 2016;20:2102-2110.

19 Poliseno L, Salmena L, Zhang J, Carver B, Haveman WJ, Pandolfi PP: A coding-independent function of gene and pseudogene mRNAs regulates tumour biology. Nature 2010;465:1033-1038.

20 Salmena L, Poliseno L, Tay Y, Kats L, Pandolfi PP: A ceRNA hypothesis: the Rosetta Stone of a hidden RNA language? Cell 2011;146:353-358.

-21 Loewer S, Cabili MN, Guttman M, Loh YH, Thomas K, Park IH, Garber M, Curran M, Onder T, Agarwal S, Manos PD, Datta S, Lander ES, Schlaeger TM, Daley GQ Rinn JL: Large intergenic non-coding RNA-RoR modulates reprogramming of human induced pluripotent stem cells. Nat Genet 2010;42:1113-1117.

22 Buckingham M, Vincent SD: Distinct and dynamic myogenic populations in the vertebrate embryo. Curr Opin Genet Dev 2009;19:444-453.

23 Erbay E, Park IH, Nuzzi PD, Schoenherr CJ, Chen J: IGF-II transcription in skeletal myogenesis is controlled by mTOR and nutrients. J Cell Biol 2003;163:931-936.

-24 Florini JR, Ewton DZ, Magri KA: Hormones, growth factors, and myogenic differentiation. Annu Rev Physiol 1991;53:201-216.

-25 Gerrard DE, Okamura CS, Ranalletta MA, Grant AL: Developmental expression and location of IGF-I and IGFII mRNA and protein in skeletal muscle. J Anim Sci 1998;76:1004-1011.

26 Hayashi S, Aso H, Watanabe K, Nara H, Rose MT, Ohwada S, Yamaguchi T: Sequence of IGF-I, IGF-II, and HGF expression in regenerating skeletal muscle. Histochem Cell Biol 2004;122:427-434.

-27 Constancia M, Hemberger M, Hughes J, Dean W, Ferguson-Smith A, Fundele R, Stewart F, Kelsey G, Fowden A, Sibley C, Reik W: Placental-specific IGF-II is a major modulator of placental and fetal growth. Nature 2002;417:945-948.

-28 Rosenthal SM, Cheng ZQ: Opposing early and late effects of insulin-like growth factor I on differentiation and the cell cycle regulatory retinoblastoma protein in skeletal myoblasts. Proc Natl Acad Sci U S A 1995;92:10307-10311.

-29 Florini JR, Magri KA, Ewton DZ, James PL, Grindstaff K, Rotwein PS: “Spontaneous” differentiation of skeletal myoblasts is dependent upon autocrine secretion of insulin-like growth factor-II. J Biol Chem 1991;266:15917-15923.

-30 Pandini G, Conte E, Medico E, Sciacca L, Vigneri R, Belfiore A: IGF-II binding to insulin receptor isoform A induces a partially different gene expression profile from insulin binding. Ann N Y Acad Sci 2004;1028:450456.

-31 Braun T, Arnold HH: Myf-5 and myoD genes are activated in distinct mesenchymal stem cells and determine different skeletal muscle cell lineages. EMBO J 1996;15:310-318.

-32 Bushati N, Cohen SM: microRNA functions. Annu Rev Cell Dev Biol 2007;23:175-205.

-33 Bartel DP: MicroRNAs: target recognition and regulatory functions. Cell 2009;136:215-233.

-34 Trapnell C, Williams BA, Pertea G, Mortazavi A, Kwan G, van Baren MJ, Salzberg SL, Wold BJ, Pachter L: Transcript assembly and quantification by RNA-Seq reveals unannotated transcripts and isoform switching during cell differentiation. Nat Biotechnol 2010;28:511-515.

-35 Guttman M, Garber M, Levin JZ, Donaghey J, Robinson J, Adiconis X, Fan L, Koziol MJ, Gnirke A, Nusbaum C, Rinn JL, Lander ES, Regev A: Ab initio reconstruction of cell type-specific transcriptomes in mouse reveals the conserved multi-exonic structure of lincRNAs. Nat Biotechnol 2010;28:503-510.

-36 Dey BK, Gagan J, Dutta A: miR-206 and -486 induce myoblast differentiation by downregulating Pax7. Mol Cell Biol 2011;31:203-214.

-37 Nakamura K, Nakano S, Miyoshi T, Yamanouchi K, Nishihara M: Loss of SPARC in mouse skeletal muscle causes myofiber atrophy. Muscle Nerve 2013;48:791-799. 


\section{Cellular Physiology Cell Physiol Biochem 2018;49:447-462 \begin{tabular}{ll|l} 
DOI: 10.1159/000492979 & $\begin{array}{l}\text { O 2018 The Author(s). Published by S. Karger AG, Basel } \\
\text { www.karger.com/cpb }\end{array}$ \\
\hline
\end{tabular} \\ Wei et al.: Lnc-SEMT Enhances Sheep Muscularity}

-38 Ge Y, Sun Y, Chen J: IGF-II is regulated by microRNA-125b in skeletal myogenesis. J Cell Biol 2011;192:6981.

-39 Cacchiarelli D, Martone J, Girardi E, Cesana M, Incitti T, Morlando M, Nicoletti C, Santini T, Sthandier O, Barberi L, Auricchio A, Musaro A, Bozzoni I: MicroRNAs involved in molecular circuitries relevant for the Duchenne muscular dystrophy pathogenesis are controlled by the dystrophin/nNOS pathway. Cell Metab 2010;12:341-351.

40 Ashmore CR, Robinson DW, Rattray P, Doerr L: Biphasic development of muscle fibers in the fetal lamb. Exp Neurol 1972;37:241-255.

-41 Maier A, McEwan JC, Dodds KG, Fischman DA, Fitzsimons RB, Harris AJ: Myosin heavy chain composition of single fibres and their origins and distribution in developing fascicles of sheep tibialis cranialis muscles. J Muscle Res Cell Motil 1992;13:551-572.

-42 O’Rourke JR, Georges SA, Seay HR, Tapscott SJ, McManus MT, Goldhamer DJ, Swanson MS, Harfe BD: Essential role for Dicer during skeletal muscle development. Dev Biol 2007;311:359-368.

43 Callis TE, Deng Z, Chen JF, Wang DZ: Muscling through the microRNA world. Exp Biol Med (Maywood) 2008;233:131-138.

44 Williams AH, Liu N, van Rooij E, Olson EN: MicroRNA control of muscle development and disease. Curr Opin Cell Biol 2009;21:461-469.

45 Prensner JR, Iyer MK, Balbin OA, Dhanasekaran SM, Cao Q, Brenner JC, Laxman B, Asangani IA, Grasso CS, Kominsky HD, Cao X, Jing X, Wang X, Siddiqui J, Wei JT, Robinson D, Iyer HK, Palanisamy N, Maher CA, Chinnaiyan AM: Transcriptome sequencing across a prostate cancer cohort identifies PCAT-1, an unannotated lincRNA implicated in disease progression. Nat Biotechnol 2011;29:742-749.

$\checkmark 46$ Weikard R, Hadlich F, Kuehn C: Identification of novel transcripts and noncoding RNAs in bovine skin by deep next generation sequencing. BMC Genomics 2013;14:789.

>47 Kretz M, Siprashvili Z, Chu C, Webster DE, Zehnder A, Qu K, Lee CS, Flockhart RJ, Groff AF, Chow J, Johnston D, Kim GE, Spitale RC, Flynn RA, Zheng GX, Aiyer S, Raj A, Rinn JL, Chang HY, Khavari PA: Control of somatic tissue differentiation by the long non-coding RNA TINCR. Nature 2013;493:231-235.

-48 Tsoi LC, Iyer MK, Stuart PE, Swindell WR, Gudjonsson JE, Tejasvi T, Sarkar MK, Li B, Ding J, Voorhees JJ, Kang HM, Nair RP, Chinnaiyan AM, Abecasis GR, Elder JT: Analysis of long non-coding RNAs highlights tissuespecific expression patterns and epigenetic profiles in normal and psoriatic skin. Genome Biol 2015;16:24.

49 Edmondson DG, Olson EN: A gene with homology to the myc similarity region of MyoD1 is expressed during myogenesis and is sufficient to activate the muscle differentiation program. Genes Dev 1989;3:628640 .

50 Moncaut N, Rigby PW, Carvajal JJ: Dial M(RF) for myogenesis. FEBS J 2013;280:3980-3990.

-51 Perry RL, Rudnick MA: Molecular mechanisms regulating myogenic determination and differentiation. Front Biosci 2000;5:D750-767.

-52 Sartorelli V, Caretti G: Mechanisms underlying the transcriptional regulation of skeletal myogenesis. Curr Opin Genet Dev 2005;15:528-535.

-53 Fatica A, Bozzoni I: Long non-coding RNAs: new players in cell differentiation and development. Nat Rev Genet 2014;15:7-21.

54 van Rooij E, Liu N, Olson EN: MicroRNAs flex their muscles. Trends Genet 2008;24:159-166.

$>55$ Zhao Y, Samal E, Srivastava D: Serum response factor regulates a muscle-specific microRNA that targets Hand2 during cardiogenesis. Nature 2005;436:214-220.

56 Rao PK, Kumar RM, Farkhondeh M, Baskerville S, Lodish HF: Myogenic factors that regulate expression of muscle-specific microRNAs. Proc Natl Acad Sci U S A 2006;103:8721-8726. 